\title{
Erratum to: Exercise increases lactoferrin, but decreases lysozyme in salivary granulocytes
}

Trevor Gillum ${ }^{1} \oplus$ - Matthew Kuennen ${ }^{2} \cdot$ Zachary McKenna $^{1} \cdot$ Micaela Castillo $^{1} \cdot$ Alex Jordan-Patterson ${ }^{1} \cdot$ Caitlin Bohnert $^{1}$

Published online: 1 June 2017

C) Springer-Verlag Berlin Heidelberg 2017

\section{Erratum to: Eur J Appl Physiol (2017)}

117:1047-1051

DOI 10.1007/s00421-017-3594-0

In the original version of this article, unfortunately second affiliation of the author is incorrect. The correct affiliation should be:

Department of Exercise Science, High Point University, High Point, NC 27268, USA

The online version of the original article can be found under doi:10.1007/s00421-017-3594-0.

Trevor Gillum

tgillum@calbaptist.edu

1 Department of Kinesiology, California Baptist University, 8432 Magnolia Ave., Riverside, CA 92504, USA

2 Department of Exercise Science, High Point University, High Point, NC 27268, USA 